Spoke cavity power coupler conceptual design work for the HEL-JTO beam exp.

B. Rusnak

October 10, 2007 
This document was prepared as an account of work sponsored by an agency of the United States government. Neither the United States government nor Lawrence Livermore National Security, LLC, nor any of their employees makes any warranty, expressed or implied, or assumes any legal liability or responsibility for the accuracy, completeness, or usefulness of any information, apparatus, product, or process disclosed, or represents that its use would not infringe privately owned rights. Reference herein to any specific commercial product, process, or service by trade name, trademark, manufacturer, or otherwise does not necessarily constitute or imply its endorsement, recommendation, or favoring by the United States government or Lawrence Livermore National Security, LLC. The views and opinions of authors expressed herein do not necessarily state or reflect those of the United States government or Lawrence Livermore National Security, LLC, and shall not be used for advertising or product endorsement purposes.

This work performed under the auspices of the U.S. Department of Energy by Lawrence Livermore National Laboratory under Contract DE-AC52-07NA27344. 
Spoke cavity power coupler conceptual design work for the HEL-JTO beam exp. done by:

\section{Brian Rusnak}

lab:

Lawrence Livermore National Laboratory, MS L-050

phone:

925/422-0435

email: $\quad \underline{\text { rusnak1@IInl.gov }}$

Objectives:

- Create a low-cost, modest-power RF coupler for a SRF spoke cavity beam test of electrons test to be done at LANL

\section{Deliverables:}

- Develop a detailed design concept of a workable coupler for the beam test

- Deliver a technical design report

\section{Work Performed:}

- Created a coupler parameter sheet as to what is being designed

- Developed a conceptual design

- Evaluated conceptual design using CST MWS transient analysis

- Improved design over successive runs to establish final design

- Evalauted potential for multipacting behavior in final design

- Generated an estimate of the external Q of the coupler

- Generatde a detailed 3D assembly model highlighting design features

- Created a Technical Design report in the form of an Excel spreadsheet to maximize info transfer while minimizing writing.

\section{Design Highlights and Commentary:}

Developing the design for this magnetically-coupled SRF spoke cavity testing coupler was basically straightforward since the cavity coupling port needed to be one of the 1.22" ID ports, and the power level was limited by the available RF to less than 400 W TW power. In addition, the coupler would be immersed in bath cryostat filled with liquid helium, and ultimately used in a pulsed mode to accelerate beam, thereby significantly relaxing the thermal loads on the coupler.

Combining the above considerations with the level of resources available for this task, emphasis was placed on rapidly developing a robust, reliable design that would use commercially-available components as available to save design, engineering, and fabrication costs. Analysis was also kept to a minimum. As such, the design incorporates the following features:

- Use of a commercially-available Type-N ceramic feedthrough. For the power and frequency range of the test, with the feedthrough immersed in LHe, it was felt the Type-N feedthrough would provide a robust, low-cost vacuum window solution.

- The coupler outer conductors would be solid OFE copper that is brazed into two 2.75" CFF, with the cavity-sde flange being rotatable to allow minor Qx adjustments by rotating the coupler. The braze joint shown has the copper brazed into a groove in the SST to ensure maximum strength for successive thermal cyclings. The outer wall of the copper between the two flanges serves as the heat sink for depositing coupler heat to the liquid helium.

- The inner conductor would be solid OFE copper brazed to the outer conductor at the top to ensure maximum thermal conductivity from the outer thermal sink area to the base of the feedthrough. A mass-reducing hole is placed down the center of the inner conductor to decrease thermal mass and weight.

- This assembly would be mated to the Type- $\mathrm{N}$ feedthrough by pushing the pin from the feedthrough into a spring-loaded connector on the base of the inner conductor, then bolting the flanges together.

- If the coupling needs to be greatly reduced, an additional 1/2" CFF can be insered between the coupler and cavity flanges. Increasing the coupling can be done with a 3 stub tuner.

Further details are included in the balance of this report.

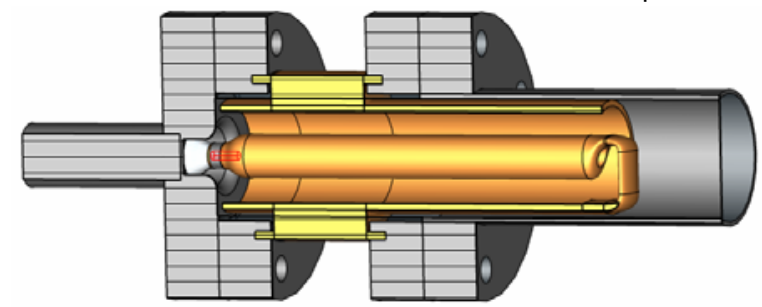

Baseline final design graphic sectioned to show detail

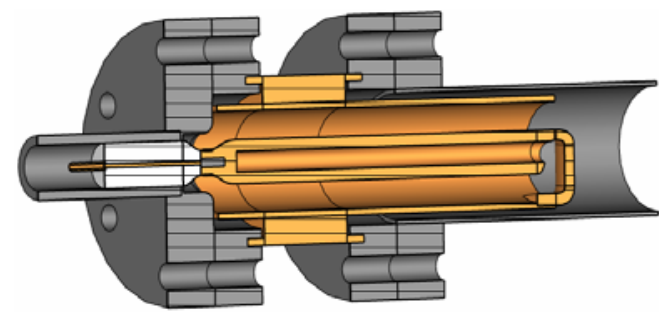

Baseline final design graphic half section 
Overall parameter sheet for coupler design process

$\begin{array}{ll}\text { orig } & 9 / 21 / 2007 \\ \text { vers } & 10 / 3 / 2007\end{array}$

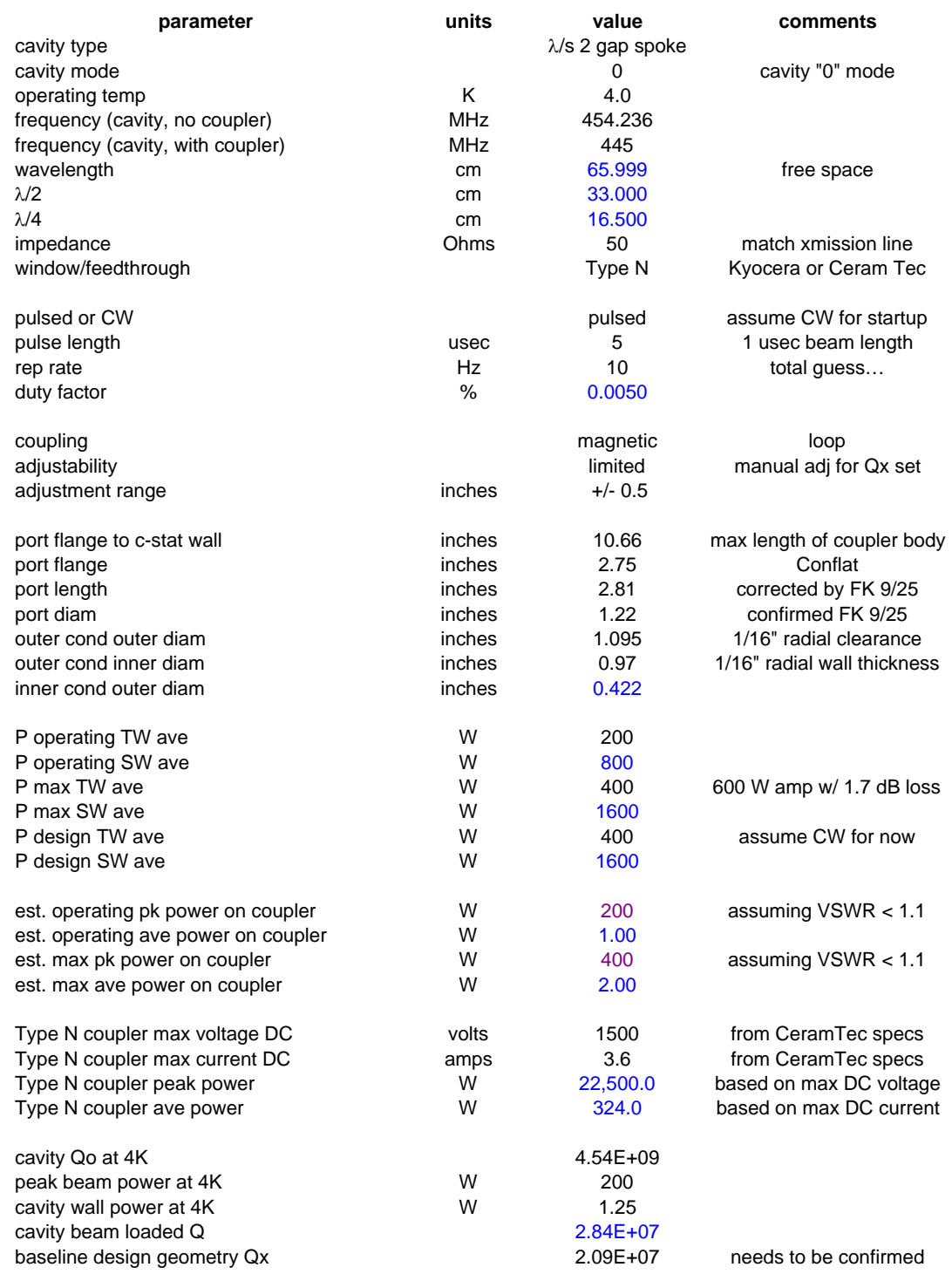

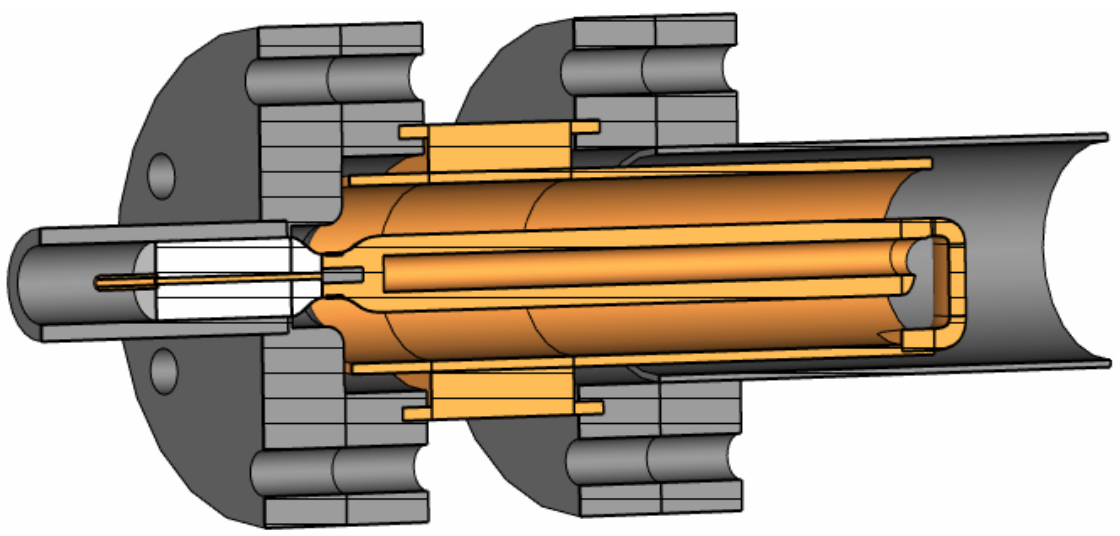

Baseline final design graphic half section 
Multipacting assessment using scaling

orig $\quad 9 / 27 / 2007$

\begin{tabular}{|cc|c|}
\hline Multipacting band scaling - based on original work \\
\cline { 3 - 3 } frequency $(\mathrm{MHz})$ & 350 & $\mathbf{4 5 4 . 2 6}$ \\
diameter $(\mathrm{mm})$ & 100 & $\mathbf{3 0 . 9 9}$ \\
impedance $(\mathrm{Ohm})$ & 50 & $\mathbf{5 0}$ \\
MP order & $\mathrm{TW}(\mathrm{kW})$ & $\mathrm{TW}(\mathrm{kW})$ \\
\hline $\mathbf{7}$ & 32 & $\mathbf{0 . 8 3 7}$ \\
$\mathbf{6}$ & 36 & $\mathbf{0 . 9 4 2}$ \\
$\mathbf{5}$ & 60 & $\mathbf{1 . 5 7 0}$ \\
$\mathbf{4}$ & 118 & $\mathbf{3 . 0 8 8}$ \\
$\mathbf{3}$ & 152 & 3.978 \\
$\mathbf{2}$ & 300 & $\mathbf{7 . 8 5 2}$ \\
$\mathbf{1}$ & 428 & $\mathbf{1 1 . 2 0 1}$ \\
\hline
\end{tabular}

For operation at less than or equal to $400 \mathrm{~W}$,

MP below about the 8th-9th order should not be supported

\begin{tabular}{|c|c|c|c|c|c|}
\hline diameter (mm) & $\mathbf{1 0 0}$ & $\mathbf{1 0 0}$ & $\mathbf{7 5}$ & $\mathbf{7 5}$ & $\mathbf{5 0}$ \\
\hline impedance (Ohm) & $\mathbf{7 5}$ & $\mathbf{5 0}$ & $\mathbf{7 5}$ & $\mathbf{5 0}$ & $\mathbf{5 0}$ \\
\hline MP Order & \multicolumn{5}{|c|}{ multipacting power band average power (kW) } \\
\hline 7 & 48 & 32 & 15 & 10 & 2 \\
\hline 6 & 52 & 36 & 16 & 11 & 2 \\
\hline 5 & 88 & 60 & 29 & 19 & 4 \\
\hline 4 & 176 & 118 & 56 & 37 & 7 \\
\hline 3 & 234 & 152 & 72 & 48 & 10 \\
\hline 2 & 448 & 300 & 146 & 97 & 19 \\
\hline 1 & 640 & 428 & 203 & 136 & 27 \\
\hline
\end{tabular}

scaled bands at $350 \mathrm{MHz}$ for travelling-wave

power from ADTF spoke cavity coupler report

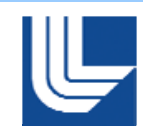

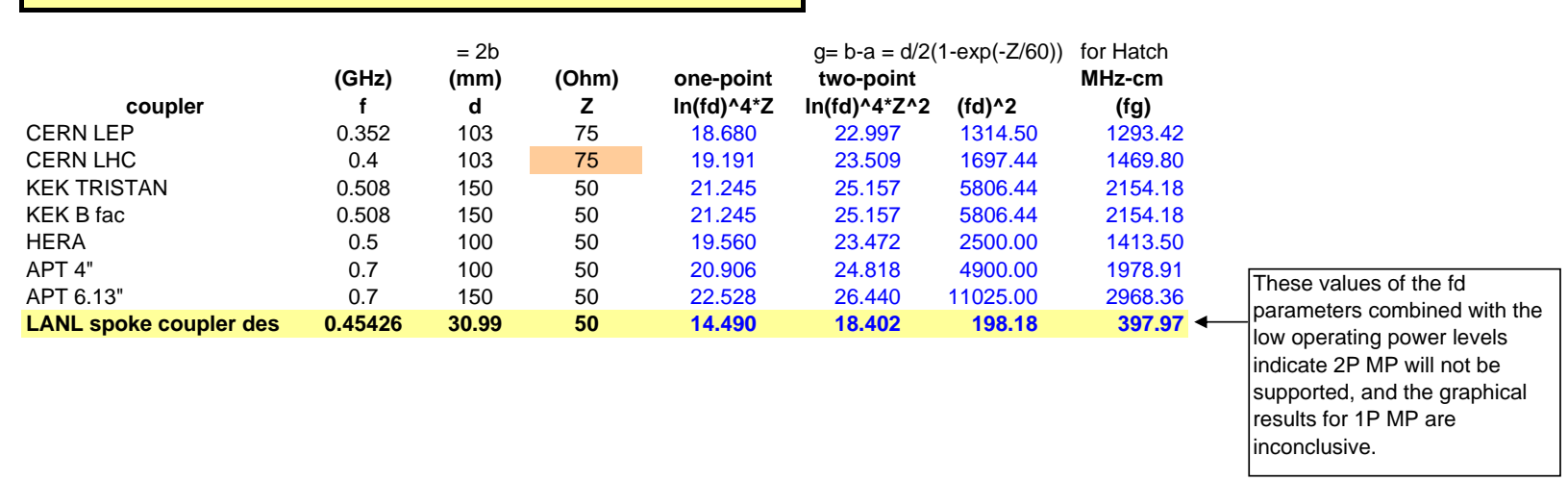

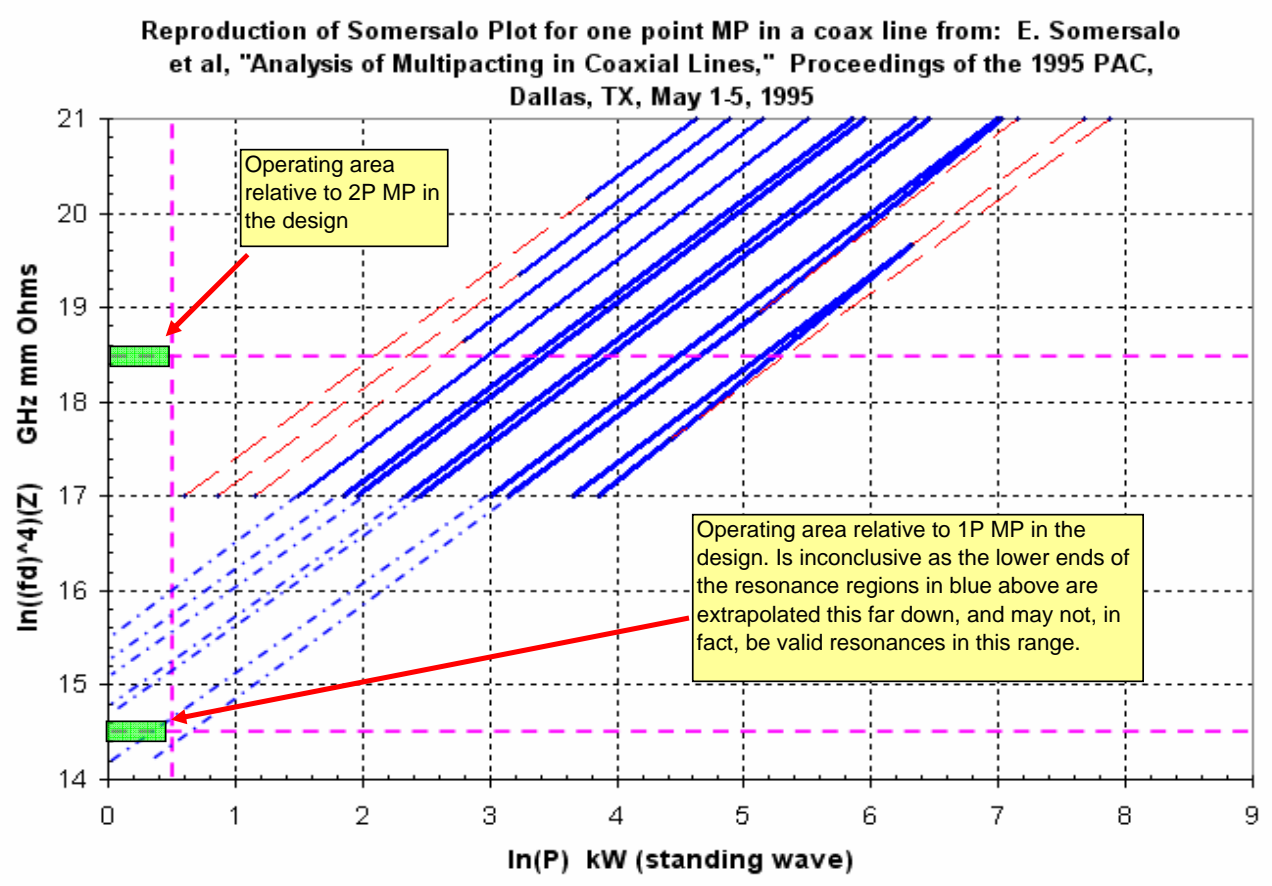


Coupler electromagnetic transient analysis on CST MWS

Simplified model for analyzing coupler parameters.

The stopband at $\sim 1300 \mathrm{MHz}$ is due to a quarter-wave resonance

that is being set up between the outer electrical conductor and the

vacuum wall (highlighted in red below). The distance between the

cavity and the base of the outer conductor (blue below) needs to be short

for higher $(>400 \mathrm{MHz})$ frequency applications.
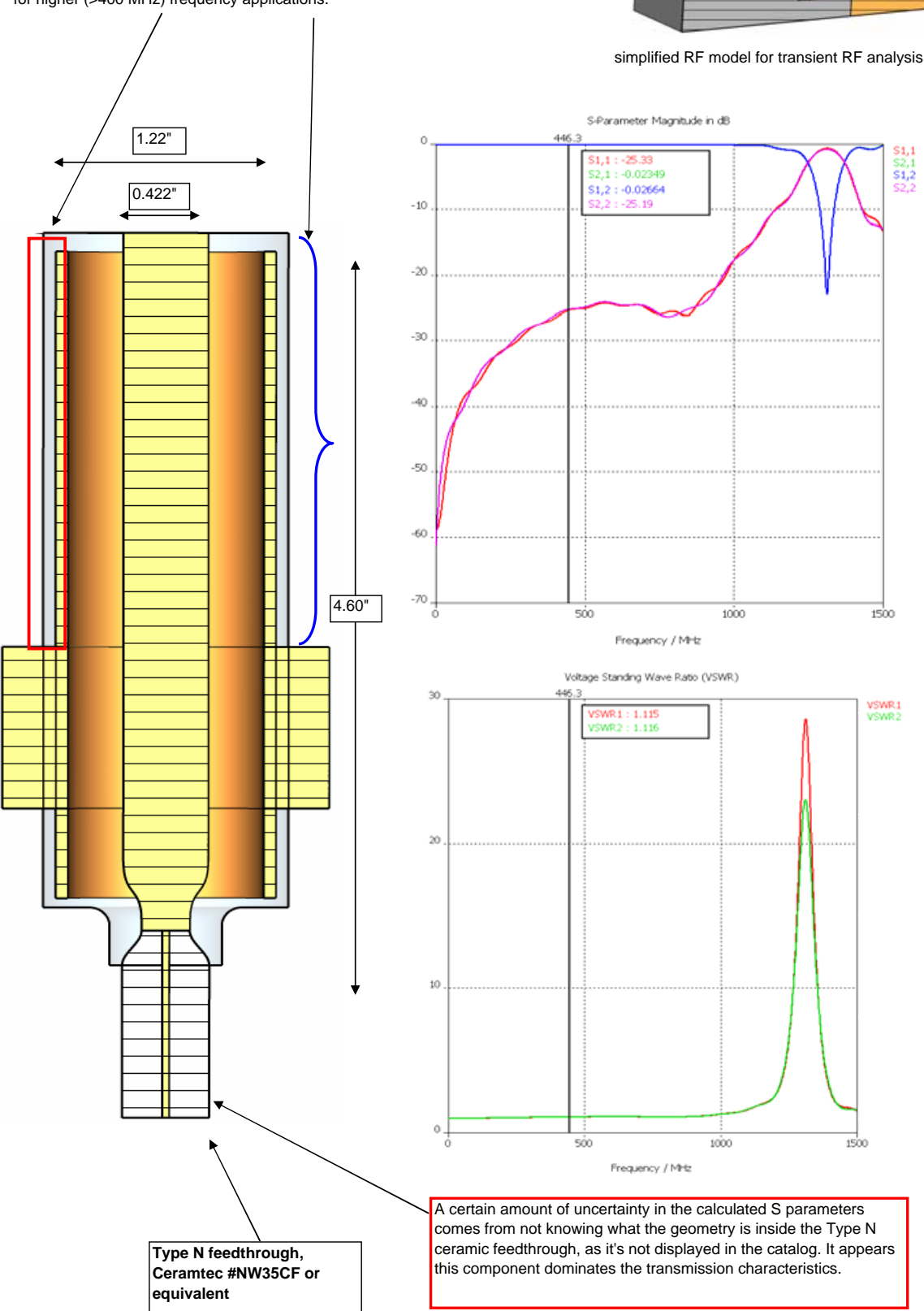

Type
Monitor
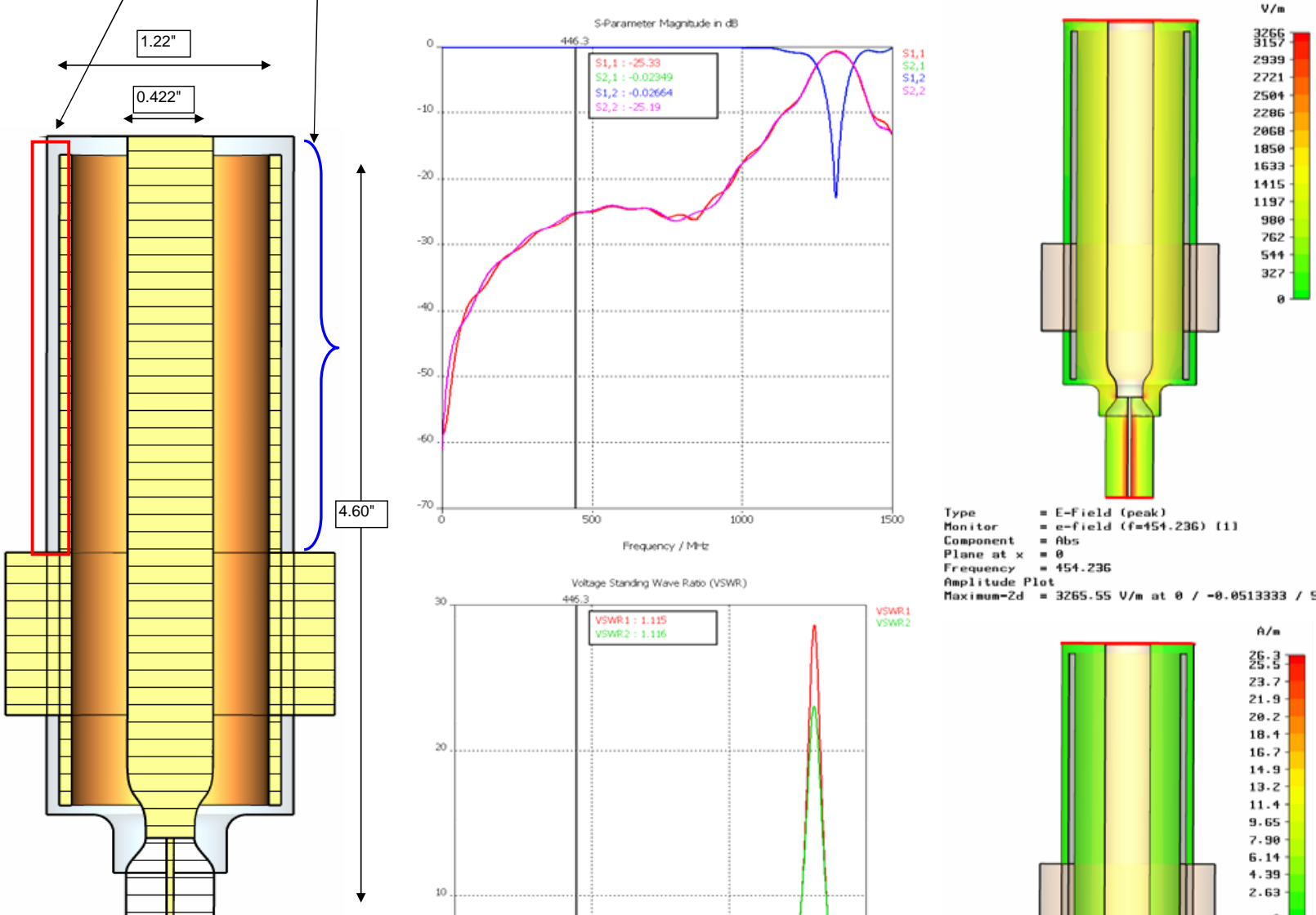

Componen

:

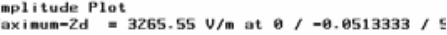

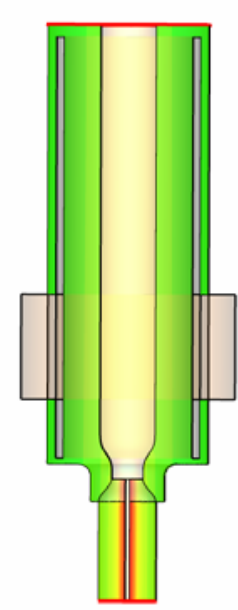

A/a

$26: 5$

23.7

20.2

18.4

16.7

14.9
13.2
11.4
9.65

9.65

7.90

6.14
4.39
2.63

2.63

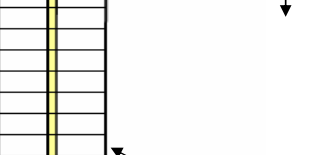

Tre Needrough,

Ceramtec \#NW35CF or

equivalent

$\begin{array}{ll}\text { Yype } & \text { H-Field (peak) } \\ & =h-f \text { ield ( } f=454.236) \text { (11 }\end{array}$

Component $=$ Abs

$\begin{aligned} \text { Plane at } x & =0 \\ \text { requency } & =454.236\end{aligned}$

requency $=454.236$

Faximum-2d $=26.3393$ a/m at a $/-0.0513333 / 4$ 


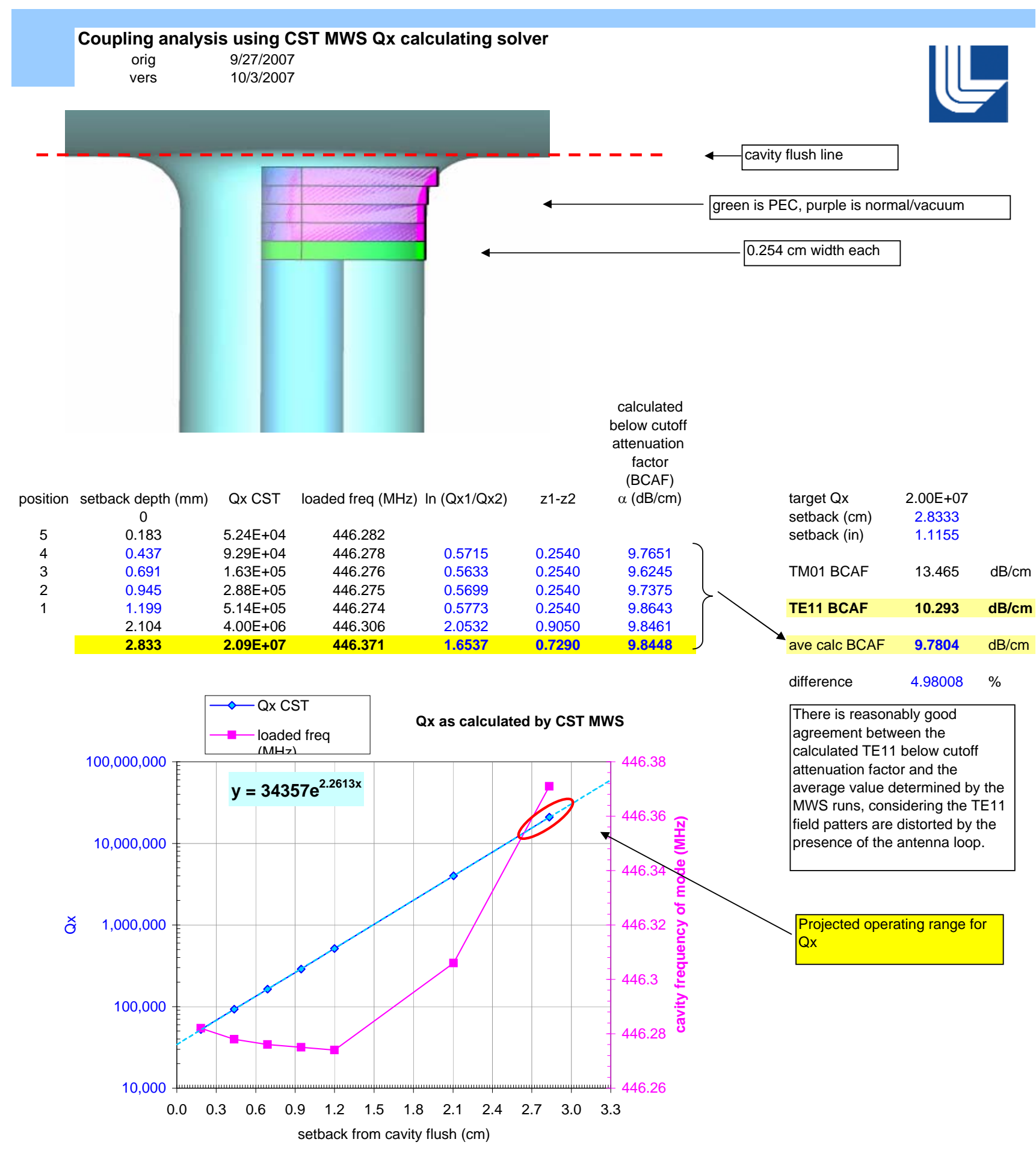

Comments on External Q analysis: The analysis was done using the Qx calculation function in MWS, vers 2006B.03. While doing this was straightforward, it was not checked against a proven alternative calculational route like a Balleyguier analysis modified for magnetic coupling loops. While the Qx values produced by MWS appear to be reasonable, and the slope is consistent with the cutoff for a 1.27" diam port, it is recommended that the above plot be confirmed with a measurement on the cavity done at LANL, instead of by doing additional analyses. This is proposed for efficiency purposes, as addtional analysis work would easily take 3-4 days, where a measurement in the lab would take $\sim 0.5$ days, and would be more rigorous. In addition, the design value needs to be confirmed by LANL for adequacy for beam loading and cavity operation bandwidth. 
Field plots around coupler loop
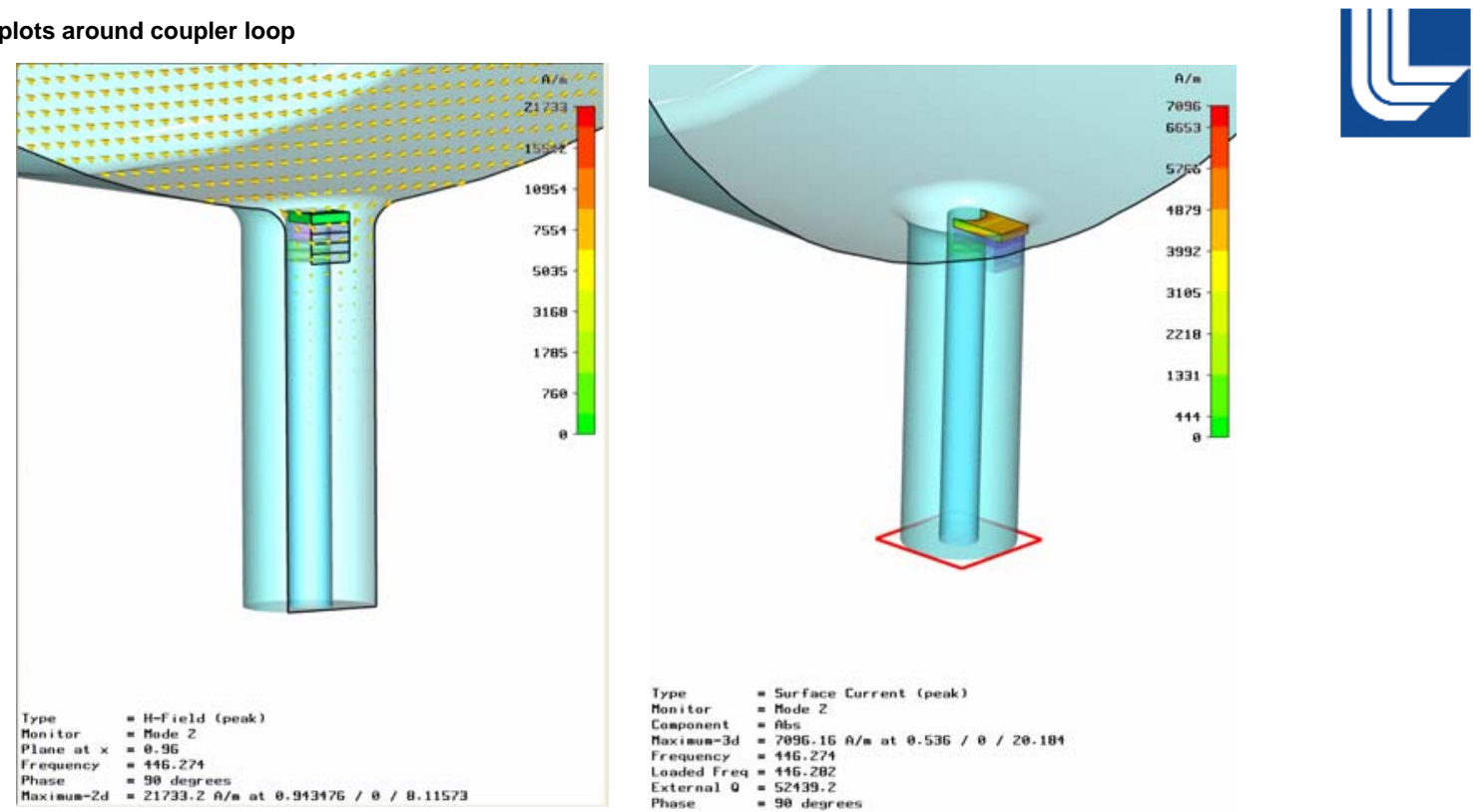

Type
Monitor
Confrace Current (peak)

Maximua-3d $=7896.16 \mathrm{~A} / \mathrm{a}$ at $0.536 / 0 / 28.184$

Frequency $=146.274$

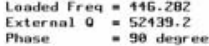

Magnetic and electric field patterns in the coupling port are analagous to TE11 mode patterns except near loop
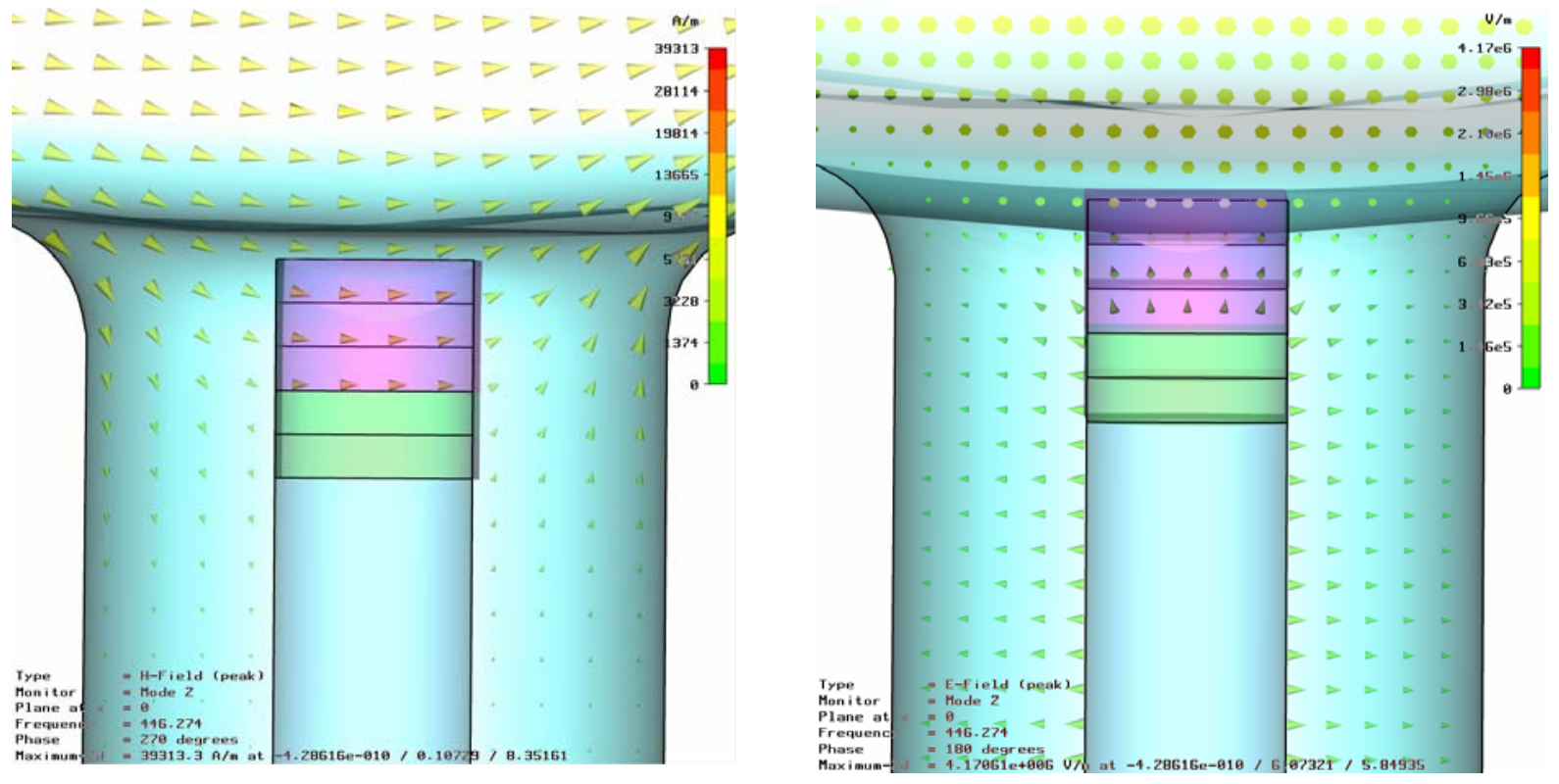


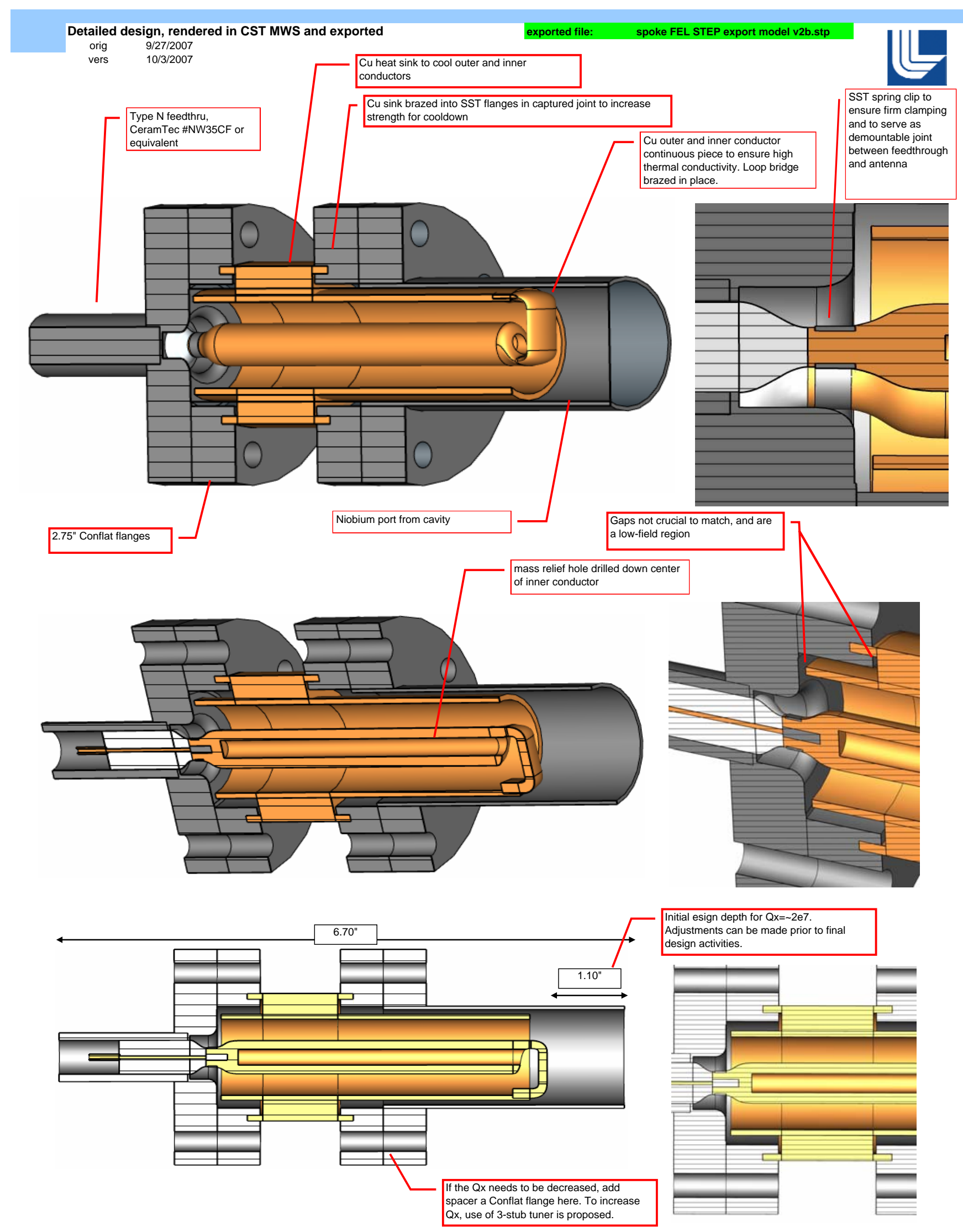

